\title{
Factors Associated with Mortality among Multidrug Resistant Tuberculosis MDR/RR-TB Patients in Democratic Republic of Congo
}

\section{Murhula Innocent Kashongwe1,2, Leopoldine Mbulula², Pierre Umba ${ }^{2}$, Francois Bompeka Lepira ${ }^{3}$, Michel Kaswa ${ }^{4}$, Zacharie Munogolo Kashongwe ${ }^{1}$}

\author{
${ }^{1}$ Lung disease Unit, Department of Internal medicine, Faculty of Medicine, University of Kinshasa Hospital, University of \\ Kinshasa, Kinshasa, Democratic Republic of Congo \\ ${ }^{2}$ Centre d'excellence Damien (CEDA), Action Damien, DR Congo \\ ${ }^{3}$ Nephrology Unit, Department of Internal Medicine, Faculty of Medicine, University of Kinshasa Hospital, University of \\ Kinshasa, Kinshasa, Democratic Republic of Congo \\ ${ }^{4}$ National Tuberculosis Program of DR Congo (NTP), DR Congo \\ Email: innocent.kashongwe@unikin.ac.cd
}

How to cite this paper: Kashongwe, M.I., Mbulula, L., Umba, P., Lepira, F.B., Kaswa, M. and Kashongwe, Z.M. (2017) Factors Associated with Mortality among Multidrug Resistant Tuberculosis MDR/RR-TB Patients in Democratic Republic of Congo. Journal of Tuberculosis Research, 5, 276-291. https://doi.org/10.4236/jtr.2017.54029

Received: November 1, 2017

Accepted: December 12, 2017

Published: December 15, 2017

Copyright $\odot 2017$ by authors and Scientific Research Publishing Inc. This work is licensed under the Creative Commons Attribution International License (CC BY 4.0).

http://creativecommons.org/licenses/by/4.0/

c) (†) Open Access

\begin{abstract}
Background: Tuberculosis remains a very common infectious disease in Democratic Republic of Congo (DRC). The resistance to drugs worsens the prognosis and the outcome of patients affected tuberculosis and increase their mortality. Objective: To identify factors associated with death among Multidrugs resistant tuberculosis (MDR/RR TB) patients referred to the referential hospital, Centre d'Excellence Damien (CEDA). Materials and Methods: A retrospective cohort study of patients attending health care to the Center CEDA, a referral center for management of MDR/RR-TB in DR Congo. This study included all MDR/RR-TB patients referred from February 1st, 2015 to February 29th, 2017. A multivariate COX regression was performed to identify factors associated with mortality in the target population. Kaplan Meier method described the survival of patients and the comparison of curves was performed by the test of log Rank. Results: 199 patients were included in our study. Male gender was predominant with a sex ratio of 1.3. The mean age of patients was $35.8 \pm 13.9$ years. Among them, 18 (15.1\%) were died. The major complications were Chronicles pulmonary Heart failure $(p=0.035)$, Chronic respiratory insufficiency $(\mathrm{p}=0.004)$, depression $(\mathrm{p}=0.044)$, undernutrition $(\mathrm{p}=0.033)$, alcohol addiction $(\mathrm{p}=0.006)$ and high smoking $(\mathrm{p}=0.019)$. In multivariated analysis, factors associated to the death were alcohol addiction $(\mathrm{HRa}=12.64,95 \% \mathrm{CI} 2.36-14.55, \mathrm{p}=0.003)$, asthenia $(\mathrm{HRa}=4.75,95 \% \mathrm{CI}$ $1.56-14.50, \mathrm{p}<0.001)$, pulmonary consolidation ( $\mathrm{HRa}=10.0195 \% \mathrm{CI} 2.34$ $12.86, \mathrm{p}=0.02$ ), some chest X-ray abnormalities such as signs of pulmonary
\end{abstract}


fibrosis $(\mathrm{HR}=4.7,95 \% \mathrm{CI} 2.78-28.94, \mathrm{p}=0.002)$ and the Chronic respiratory insufficiency $(\mathrm{HRa}=3.77,95 \%$ CI $1.37-10.43, \mathrm{p}=0.010)$. Conclusion: The present retrospective cohort study revealed that structural and functional pulmonary alteration emerged as the main factors associated with mortality among MDR/RR TB patients in Kinshasa. National Tuberculosis Programs should take into account those parameters while defining mortality reduction strategy.

\section{Keywords}

MDR/RR-TB, Mortality, Kinshasa, Factors

\section{Introduction}

The infection of Mycobacterium tuberculosis (TB) remains one of top ten causes of death in the world, where resource-limited countries are most affected by the disease. The World Health Organization (WHO) has set an objective to reduce by $95 \%$ the absolute number of $\mathrm{TB}$ deaths in affected countries with ideal to reach this goal by 2035 [1] [2]. To reach this TB end point objective, prior identification of causes of TB related deaths and their risk factors are required to develop appropriated measures and preventive strategies [3]. In DRC, the TB mortality rate is estimated at 54 for hundred thousand habitants, and the goal for National programme against TB (NTP) is to reduce this mortality rate to 40 per hundred thousand by 2017 [1] [2]. However, the achievement of this goal might be hampered by the emergency of TB drug-resistant strains, which are responsible for treatment failure and subsequent mortality [4] [5]. Indeed, among the 132,120 cases of multidrug resistant/Rifampicin resistant tuberculosis (MDR/RR-TB) that were reported in 2016, Word Health Organization (WHO) 1200 originated from DRC; TB mortality were $18 \%$ under TB treatment [1] [5].

The management of MDR/RR-TB cases in DRC has been based on the treatment and monitoring of diagnosed cases as ambulatory patients, this policy has been applied since the detection of first cases of MDR-TB in 1994 [6]. Management of these patients was initially centered in the Kinshasa university Hospital. From 2012, follow up of MDR/RR-TB patients have been organized within 35 health centers for diagnosis and treatment (CSDT) of MDR/RR-TB; these centers are in different health zones of Kinshasa city [5]. In the context of low-incomes and resource-limited country, hospitals and health centers of DRC face difficulties to hospitalize TB patients who require appropriate and specific cares. The NTP of DRC had requested and obtained a support from a non-profit organization called "Action Damien" for the construction of a referral and specialized center for TB cases: Damien Excellence center "centred" excellence Damien' (CEDA). This hospital has a capacity of 24 beds dispatched in 5 wards, and various services and cares can be provided to TB patients including nutritional support, laundry and outpatient consultation and treatment. The main 
goal of this center is to improve the life quality and prognosis of TB patients through the management of side effects related to TB treatment, and complicated cases of TB, including the MDR/RR-TB cases reported in the Kinshasa city.

Previous studies have reported various factors that have been associated with increased mortality among TB patients [3] [7], and commonly reported factors include the TB multi drug resistance, HIV infection, diabetes mellitus, malignancy, alcohol and malnutrition [3]. Risk of death for a TB patient increases with number of risk factors presents in the same patient [7].

In DRC, risk factors associated with TB mortality have not been well studied or only scarce information is available. With the increasing number of MDR/RR-TB cases reported in DRC, it has become crucial to identify the factors associated with MDR-TB occurrence and their consecutive mortality [1]. The development of an appropriated strategy to tackle TB mortality in Kinshasa and DRC will rely on the management those risk factors with appropriate preventive measures.

The study aimed to identify factors associated with mortality among MDR/RR-TB patients in Kinshasa in DRC.

\section{Materials and Methods}

\subsection{Study Type and Site of Study}

We conducted a retrospective cohort study to identify risk factors of MDR/RR-TB mortality. Clinical records of MDR/RR-TB patients who were referred to The Kinshasa TB referral hospital CEDA during the period from February first, 2015 to February 29, 2017 were collected for this study purpose. Most of these patients were directly referred from the 35 health centers for diagnosis and ambulatory management of MDRTB patients (CSDT), these centers are found in different sites of Kinshasa (Figure 1). Recorded information of interest was collected from the patients' admission in the hospital, their anti-tuberculosis treatment to the completion or death. Patients information were collected following a designed protocol that included sociodemographic information, clinical manifestations and laboratory analysis such as blood analysis and radiologic results, the reason for hospitalization and the outcome following the hospitalization, death or cure.

All available files of MDR/RR-TB cases hospitalized in the CEDA during the period of our study window were enrolled. Cases of drug resistance other than MDR/RR-TB such as extensively drug-resistance TB (XDR-TB) and pre-XDR-TB were excluded from the current study. All MDR/RR-TB patients admitted in the CEDA were already under anti-tuberculosis treatment following the regimen recommended by the NTP of DRC. This regimen includes Kanamycin $(\mathrm{Km})$, Moxifloxacin (Mfx), Prothionamide (Pfo), Clofazimin (Clz) Isoniazid (INH), Ethambutol (E) and Pyrazinamide ( $\mathrm{Z}$ ); the regimen covers a period of 9 months treatment and is divided in 2 rounds $4 \mathrm{~km} \mathrm{MfxPtoClz} \mathrm{H} \mathrm{E} \mathrm{Z/5} \mathrm{MfxClz} \mathrm{E} \mathrm{Z.}$ 


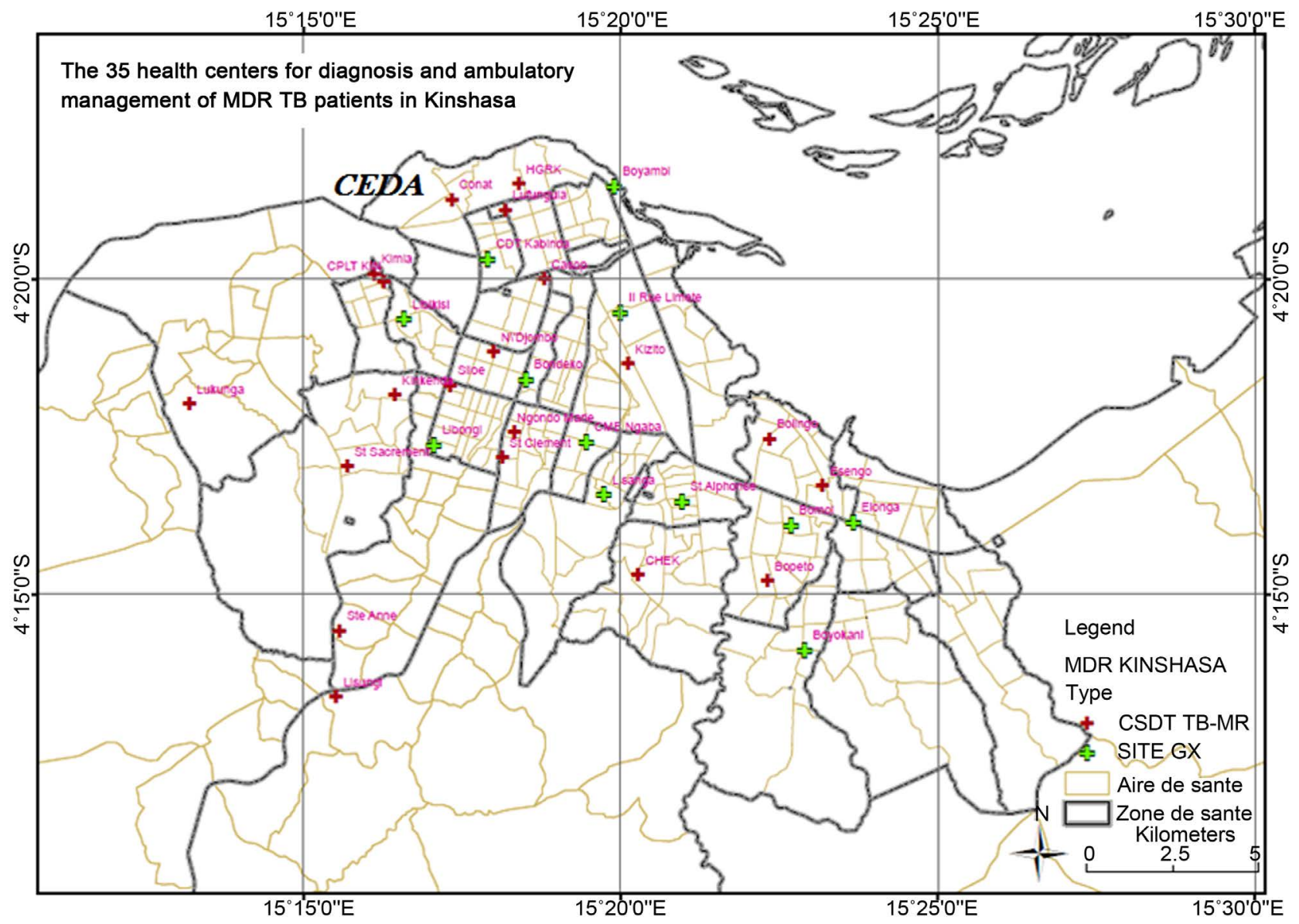

Figure 1. Map of Health centers for diagnosis of treatment of MDR/RR-TB in Kinshasa.

\subsection{Conceptual Definition of Terms}

For an objective interpretation of patients' results, we have provided a conceptual definition to some terms used in this study:

- Anemia not tolerated: when the Hemoglobin rate if less than $10 \mathrm{~g} / \mathrm{dl}$ with tachycardia, shortness of breath and dizziness.

- Asthma: When a patient had a known history of asthmatic disease or symptoms, wheezing and acute chest syndrome, with symptoms revolving with bronchodilator administration.

- Asthenia: per WHO performance scale when the score is higher than 1.

- Atelectasis: Chest X-ray showing hilar triangular opacity with diaphragmatic attraction [8].

- Cavitary syndrome: radiographic images of pulmonary roundness, single or multiple, surrounded by an irregularly contoured wall, resulting from the destruction of the parenchyma of the lungs sometimes associated with a drainage bronchus [8].

- Chronic pulmonary obstructive disease (COPD): when the spirometry Tiffeneau-Pinelli index is less than 70 (Tiffeneau-Pinelli $<70$ ).

- Chronic pulmonary heart disease: right ventricular pressure overload and dilatation of the right ventricle on echocardiography. 
- Chronic respiratory insufficiency: respiratory distress, clubbing, cyanosis, hypoxemia and/or hypercapnia, retracted and calcified pulmonary radiological image.

- Coma: Loss of consciousness with a Glasgow Score of less than 10.

- Death: irreversible cardiorespiratory arrest. Death certificate mentioning the date and time of death.

- Depression: Hospital Anxiety and Depression Scale (HAD). Total > 11 with specialized opinion of the Neuro Psycho Pathological Center (CNPP) of Kinshasa [9].

- Diabetes Mellitus: History of Diabetes, Fasting Glucose $>126 \mathrm{mg} / \mathrm{dl}$ twice with glycated hemoglobin $>6 \mathrm{IU} / \mathrm{L}$.

- Extensively drug resistance tuberculosis (XDR TB): This is a multidrug-resistant tuberculosis with fluoroquinolone resistance and resistance to at least one of three second-line injectable drugs (amikacin, capreomycin and kanamycin) [1].

- Pre-Extensively Drug resistance tuberculosis (pre-XDR TB): This is a multi-drug resistant tuberculosis with fluoroquinolone resistance or resistance to at least one of the three second-line injectable drugs (amikacin, capreomycin and kanamycin) [1].

- HIV: when two tests with different principles of detection of HIV Antibodies were positive, determine and unigold were used [6] [10].

- Hydropneumothorax: chest X-ray showing air and fluid in the pleural space.

- Hypertension: Blood pressure > 140/90 mmHg and history of Hypertension.

- Malaria: the diagnosis was made in the presence of a positive thick spot or a positive plasmodium falciparum rapid diagnostic test [11].

- Multidrug-Resistant Tuberculosis (MDR-TB): it is a tuberculosis whose germ is resistant to the two major first line anti-tuberculosis drugs: isoniazid and rifampicin [1].

- Pleural effusion syndrome: abolition of the transmission of vocal vibrations, abolition of vesicular murmur and fluid dullness [8].

- Pulmonary consolidation: clinical and radiological signs of pulmonary consolidation [8].

- Pulmonary embolism: Thrombus in the pulmonary artery was confirmed by computed Tomography pulmonary angiography [12].

- Pulmonary fibrosis: Chest X-ray and thoracic Tomodensitometry with interstitial, retraction, calcifications and/or destroyed lung [8].

- Rifampicin Resistant Tuberculosis (RR TB): This is a tuberculosis whose germ is resistant to rifampicin diagnosed by the phenotypic or genotypic method with or without resistance to other antituberculosis drugs [1].

- Sepsis: Systolic blood pressure $\leq 100 \mathrm{~mm} \mathrm{Hg}$, Respiratory rate $\geq 22 / \mathrm{min}$, Confusion, SOFA score increase of at least 2 points and/or positive blood culture [13].

- Stroke: CT scan image showing cerebral infraction foci, cerebral edema, he- 
matoma or an intracerebral hemorrhage.

- Thrombophlebitis: venous doppler ultrasound of the lower extremities showing a thrombus [12].

- Undernutrition: Body Mass Index (BMI) $<18 \mathrm{~kg} / \mathrm{m}^{2}[14]$.

\subsection{Statistical Analysis}

Data were input and analyzed using the statistical software SPSS 21 (IC Chicago).

Descriptive data were presented as mean with their standard deviations for normally distributed variables. Comparison between two groups was measured using $t$ student test for continuous variables, Chi-square or $\mathrm{F}$ fisher tests were used to compare categorical variable data. Cox regression analysis was used to determine the predictors of mortality among MDR/RR-TB patients, reporting hazard ratio (HR) with a 95\% confidence interval (CI). Kaplan-Meier survival analysis was applied to describe the survival rate between the date of admission in the hospital and the end-point, death (completed) or discharge of the patient (censored). Log-rank test was used to compare the survival curves between the two groups. Only curves with statistical significance were considered in this study, for a $\mathrm{p}<0.05$ data were considered as statistical significant.

\section{Results}

\subsection{General Characteristics}

One hundred nineteen patients with confirm MDR/RR-TB were admitted in the Damien Excellence Center during the study window time of our research. Most patients were male with a sex ratio of 1.3. The mean age of participant was 35.8 (13.9) years old. Eighteen patients (15.1\%) died during their admission in the hospital. In addition, more than half of MDR/RR-TB (60.5\%) patients were single, and patients without occupation were dominant with about a third of participants (35.3\%) (Table 1 ).

Information about symptoms, clinical signs and laboratory analysis were collected from patients' file when available. Cough (74.8\%) and dyspnea (64.7\%) were the most frequents symptoms presented by the patients (Table 2), while weight loss (71.4\%) and fever (64.7\%) were predominant general signs. Pulmonary consolidation and respiratory distress syndrome constituted the main major signs with $62.2 \%$ and $26.9 \%$ respectively (Table 2 ). Three patients MDR/RR-TB patients were admitted for a coma; two patients had Stroke and one patient had coma due to hypoglycemia.

An increase of white blood cells count was observed in the group of patients who died during the admission time in hospital (Table 3). Radiologic results were marked by suggesting lesions of combine alveolar and interstitial syndrome $(\mathrm{p}=0.018)$ or pulmonary fibrosis $(\mathrm{p}=0.013)$, who were associated with death. Interestingly, nine cases among TB patients had a diagnosis of sepsis where Klebsiella pneumoniae (K. penuomiae), K. oxytoca and Pseudomonas aeruginosa 
Table 1. General characteristics of patients by following event outcome.

\begin{tabular}{ccccc}
\hline Variables & $\begin{array}{c}\text { All } \\
n=119\end{array}$ & $\begin{array}{c}\text { Deceased } \\
n=18\end{array}$ & $\begin{array}{c}\text { Alive } \\
n=101\end{array}$ & $p$ \\
\hline Age (years) & $35.8 \pm 13.9$ & $38.4 \pm 19.3$ & $35.4 \pm 12.7$ & 0.393 \\
Sex $\boldsymbol{n}$ (\%) & & & & 0.460 \\
Male & $68(57.1)$ & $11(61.1)$ & $57(56.4)$ & \\
Female & $51(42.9)$ & $7(38.9)$ & $44(43.6)$ & \\
Marital status $\boldsymbol{n}(\%)$ & & & & \\
Married & $41(34.4)$ & $6(33.3)$ & $35(34.7)$ & \\
Single & $72(60.5)$ & $10(55.6)$ & $62(61.4)$ & \\
Widow/widower & $6(5.0)$ & $2(11.1)$ & $4(4.0)$ & \\
Profession $\boldsymbol{n}(\%)$ & & & & \\
Student & $17(14.3)$ & $5(27.8)$ & $12(11.9)$ & \\
trader & $14(11.8)$ & $1(5.6)$ & $13(12.9)$ & \\
teacher & $3(2.5)$ & $2(11.1)$ & $1(1.0)$ & \\
Mechanic & $6(5.0)$ & $1(5.6)$ & $5(5.0)$ & \\
Carpenter & $7(5.9)$ & $0(0.0)$ & $7(6.9)$ & \\
Health worker & $5(4.2)$ & $0(0.0)$ & $5(5.0)$ & \\
No profession & $42(35.3)$ & $7(38.9)$ & $35(34.7)$ & \\
Freelancer & $25(21.0)$ & $2(11.1)$ & $23(22.8)$ & \\
\hline & & &
\end{tabular}

were the isolated bacteria in blood culture of five patients (Table 3).

Information on complications and co-morbidity among MDR/RR-TB patients were collected to determine whether there was any pattern in the deceased group (Table 4). Undernutrition (59.7\%) and severe anemia (42.8\%) were most frequent. Proportion of depression, chronic respiratory insufficiency and chronic pulmonary heart disease were high among patients who died during their hospitalization (Table 4).

\subsection{Factors Associated with Mortality}

A univariate logistic regression was used to identify risk factors associated with mortality among MDR/RR-TB patients (Table 5), and statistical significance was observed with Chronic pulmonary heart disease, asthenia, alcohol, presence of pulmonary consolidation, combine alveolar and interstitial syndrome, and pulmonary fibrosis. A multivariate analysis was subsequently applied to assess the effect of multiple factor on the mortality of MDR/RR-TB patients. Five independent factors remained significantly associated with death; these factors include asthenia, the presence of pulmonary consolidation, chronic respiratory insufficiency, chronic pulmonary heart disease, alcohol and pulmonary fibrosis (Table 5). Alcohol increased the risk of death by 13 times, followed by pulmonary consolidation with 10 times the risk of death. 
Table 2. Clinical characteristic of patients according to vital outcome.

\begin{tabular}{|c|c|c|c|c|}
\hline Variables & $\begin{array}{c}\text { All } \\
n=119\end{array}$ & $\begin{array}{c}\text { Deceased } \\
n=18\end{array}$ & $\begin{array}{c}\text { Alive } \\
n=101\end{array}$ & $p$ \\
\hline Number of of previous TB. & & & & 0.942 \\
\hline $1 n(\%)$ & $44(45.4)$ & $7(46.7)$ & $37(45.1)$ & \\
\hline $2 n(\%)$ & $36(37.1)$ & $5(33.3)$ & $31(37.8)$ & \\
\hline$\geq 3 n(\%)$ & $17(17.5)$ & $3(20.0)$ & $14(17.1)$ & \\
\hline Asthma. $n(\%)$ & $2(1.7)$ & $0(0.0)$ & $2(2.0)$ & 0.719 \\
\hline HIV. $n(\%)$ & $11(9.2)$ & $1(5.6)$ & $10(9.9)$ & 0.479 \\
\hline COPD. $n(\%)$ & $5(4.2)$ & $1(5.6)$ & $4(4.0)$ & 0.566 \\
\hline Hypertension. $n(\%)$ & $3(2.5)$ & $2(11.1)$ & $1(1.0)$ & 0.059 \\
\hline Tabac. $n(\%)$ & $12(10.1)$ & $4(22.2)$ & $8(7.9)$ & 0.082 \\
\hline Cannabis & $4(3.4)$ & $2(11.1)$ & $2(2.0)$ & 0.108 \\
\hline Number of year pack & $11.7 \pm 7.7$ & $22.0 \pm 6.8$ & $9.6 \pm 6.5$ & 0.019 \\
\hline Alcohol. $n(\%)$ & $7(5.9)$ & $3(16.7)$ & $4(4.0)$ & 0.006 \\
\hline Systolic blood pressure. $\mathrm{mmHg}$ & $98.3 \pm 24.3$ & $96.7 \pm 26.7$ & $98.6 \pm 23.9$ & 0.761 \\
\hline Diastolic blood pressure. $\mathrm{mmHg}$ & $63.9 \pm 10.3$ & $63.3 \pm 14.6$ & $64.0 \pm 9.4$ & 0.799 \\
\hline Cardiac frequency. $\mathrm{bpm}$ & $107.2 \pm 20.6$ & $110.9 \pm 23.1$ & $106.6 \pm 20.3$ & 0.427 \\
\hline Respiratory frequency.cpm & $31.3 \pm 8.5$ & $36.9 \pm 10.1$ & $30.5 \pm 7.9$ & 0.007 \\
\hline Temperature. ${ }^{\circ} \mathrm{C}$ & $36.8 \pm 2.1$ & $36.7 \pm 0.9$ & $36.9 \pm 2.3$ & 0.677 \\
\hline $\mathrm{SaO}_{2} \cdot \%$ & $93.3 \pm 7.5$ & $89.6 \pm 4.8$ & $93.9 \pm 7.7$ & 0.045 \\
\hline BMI. kg/m² & $16.8 \pm 3.7$ & $16.5 \pm 4.7$ & $16.9 \pm 3.5$ & 0.719 \\
\hline$<15$ & $36(30.3)$ & $8(44.4)$ & $28(27.7)$ & \\
\hline $15-17$ & $35(29.4)$ & $3(16.7)$ & $32(31.7)$ & \\
\hline $17.1-18.4$ & $17(14.3)$ & $4(22.2)$ & $13(12.9)$ & \\
\hline $18.5-24.9$ & $26(21.8)$ & $2(11.1)$ & $24(23.8)$ & \\
\hline Pulmonary consolidation. $n(\%)$ & $74(62.2)$ & $4(22.2)$ & $70(69.3)$ & $<0.001$ \\
\hline Pleural effusion syndrome. $n(\%)$ & $2(1.7)$ & $0(0.0)$ & $2(2.0)$ & 0.719 \\
\hline Pneumothorax. $n(\%)$ & $4(3.4)$ & $0(0.0)$ & $4(4.0)$ & 0.514 \\
\hline Sibilant. $n(\%)$ & $4(3.4)$ & $0(0.0)$ & $4(4.0)$ & 0.514 \\
\hline Coma. $n(\%)$ & $3(2.5)$ & $1(5.6)$ & $2(2.0)$ & 0.391 \\
\hline Respiratory distress. $n(\%)$ & $32(26.9)$ & $1(5.6)$ & $31(30.7)$ & 0.019 \\
\hline
\end{tabular}

Table 3. Paraclinical characteristics of patients according to vital outcome.

\begin{tabular}{ccccc}
\hline Variables & $\begin{array}{c}\text { All } \\
n=119\end{array}$ & $\begin{array}{c}\text { Deceased } \\
n=18\end{array}$ & $\begin{array}{c}\text { Alive } \\
n=101\end{array}$ & $p$ \\
\hline Hemoglobin. g/dl & $9.8 \pm 2.2$ & $9.2 \pm 2.8$ & $9.8 \pm 2.1$ & 0.310 \\
white blood cell. elts $/ \mathrm{mm}^{3}$ & $9543.8 \pm 3893.9$ & $12,743.8 \pm 5129.6$ & $9282.6 \pm 3687.9$ & 0.015 \\
alv and interstitial sign. $n(\%)$ & $11(93.3)$ & $18(100.0)$ & $94(93.0)$ & 0.018 \\
Cavitarysyndrom. $n(\%)$ & $90(75.6)$ & $13(72.2)$ & $77(76.2)$ & 0.459 \\
Atelectasis. $n(\%)$ & $3(2.5)$ & $0(0.0)$ & $3(3.0)$ & 0.609 \\
Pulmonary Fibrosis. $n(\%)$ & $9(7.6)$ & $3(16.7)$ & $6(5.9)$ & 0.013 \\
Hydropneumothorax. $n(\%)$ & $6(5.0)$ & $2(11.1)$ & $4(4.0)$ & 0.224 \\
Stroke $n(\%)$ & $2(1.7)$ & $2(11.1)$ & $0(0)$ & 0.281 \\
Bloodculture positive $n(\%)$ & $5(4.2)$ & $2(11.1)$ & $3(16.6)$ & 0.566 \\
\hline
\end{tabular}


Table 4. Complications and comorbidities of patients according to vital outcome.

\begin{tabular}{ccccc}
\hline Variables & $\begin{array}{c}\text { All } \\
n=119\end{array}$ & $\begin{array}{c}\text { Deceased } \\
n=18\end{array}$ & $\begin{array}{c}\text { Alive } \\
n=101\end{array}$ & $p$ \\
\hline Undernutrition. $n(\%)$ & $71(59.7)$ & $15(83.3)$ & $56(55.4)$ & 0.033 \\
Anemia not tolerated. $n(\%)$ & $51(42.8)$ & $10(55.6)$ & $41(40.6)$ & 0.178 \\
ChronicResp insufficiency. $n(\%)$ & $21(17.6)$ & $8(44.4)$ & $13(12.9)$ & 0.004 \\
Malaria. $n(\%)$ & $20(16.8)$ & $1(5.6)$ & $19(18.8)$ & 0.147 \\
Sepsis. $n(\%)$ & $9(7.6)$ & $3(16.7)$ & $6(5.9)$ & 0.136 \\
Chronic pulmonary heart. $n(\%)$ & $7(5.9)$ & $3(16.7)$ & $4(4.0)$ & 0.035 \\
Diabetes Mellitus. $n(\%)$ & $7(5.9)$ & $3(16.7)$ & $4(4.0)$ & 0.069 \\
Depression. $n(\%)$ & $6(5.0)$ & $3(16.7)$ & $3(3.0)$ & 0.044 \\
Thrombophlebitis. $n(\%)$ & $3(2.5)$ & $1(5.6)$ & $2(2.0)$ & 0.391 \\
Coma. $n$ (\%) & $3(2.5)$ & $2(2.0)$ & $1(5.6)$ & 0.391 \\
Pulmonary embolism. $n(\%)$ & $2(1.7)$ & $1(5.6)$ & $1(1.0)$ & 0.281 \\
\hline
\end{tabular}

Table 5. Factors associated with mortality.

\begin{tabular}{|c|c|c|c|c|}
\hline \multirow{2}{*}{ Variables } & \multicolumn{2}{|c|}{ Univariate analysis } & \multicolumn{2}{|c|}{ Multivariate analysis } \\
\hline & $p$ & $H R(95 \% \mathrm{CI})$ & $p$ & $\operatorname{HRa}(95 \% \mathrm{CI})$ \\
\hline \multicolumn{5}{|c|}{ Chronic pulmonary heart } \\
\hline No & & 1 & & 1 \\
\hline Yes & 0.015 & $3.08(1.89-10.66)$ & 0.465 & $1.72(0.41-7.39)$ \\
\hline \multicolumn{5}{|l|}{ Asthenia } \\
\hline No & & 1 & & 1 \\
\hline Yes & $<0.001$ & $11.55(4.44-30.02)$ & 0.006 & $4.75(1.56-14.50)$ \\
\hline \multicolumn{5}{|l|}{ Alcohol } \\
\hline No & & 1 & & 1 \\
\hline Yes & 0.005 & $3.42(1.99-11.84)$ & 0.003 & $12.64(2.36-14.55)$ \\
\hline \multicolumn{5}{|c|}{ Pulmonary consolidation } \\
\hline No & & 1 & & 1 \\
\hline Yes & $<0.001$ & $7.27(2.39-22.15)$ & 0.002 & $10.01(2.34-12.86)$ \\
\hline \multicolumn{5}{|c|}{ Alveolar and interstitial image } \\
\hline No & & 1 & & 1 \\
\hline Yes & 0.011 & $4.23(1.39-12.87)$ & 0.493 & $1.65(0.39-6.89)$ \\
\hline \multicolumn{5}{|c|}{ Pulmonary Fibrosis } \\
\hline No & & 1 & & 1 \\
\hline Yes & 0.015 & $4.05(1.17-14.01)$ & 0.006 & $3.74(1.79-17.68)$ \\
\hline \multicolumn{5}{|c|}{ Undernutrition } \\
\hline No & & 1 & & 1 \\
\hline Yes & 0.037 & $2.76(1.06-7.16)$ & 0.716 & $1.24(0.38-4.04)$ \\
\hline \multicolumn{5}{|c|}{ Chronic pulmonary insufficiency } \\
\hline No & & 1 & & 1 \\
\hline Yes & 0.005 & $3.82(1.51-9.69)$ & 0.010 & $3.77(1.37-10.43)$ \\
\hline
\end{tabular}




\subsection{Survival of Analysis}

The probability of patients' survival following MDR/RR-TB hospitalization was $88.2 \%, 87.4 \%$ and $84.9 \%$ respectively at 1,2 and 3 months of cases management (Figure 2). The first month of treatment initial was the most critical in cases management with $11.8 \%$ of death. The global median of survival among all patients was 2 months (IQR: 1.5 - 4).

Since cough was the main symptoms at admission, we compared the survival rate between patient with or without patients (Figure 3), survival rate was higher in the group of patients without cough than with cough $(\mathrm{p}=0.017)$. Similar result was also observed when patient survival was compared following the presence of pulmonary fibrosis, survival rate was reduced among patient with fibrosis $(\mathrm{p}=0.039)$.

All patients had received some medication depends on the cicrumstances of the case: Hypercaloric diet, oxygen therapy, antimalarial drugs, corticoid, antibiotique, bronchodilators, antiretroviral therapy, insulin therapy, anxiolytic, anticoagulant, thoracic drainage, hypertonic dextrose injection and antitubercular drugs were given.

\section{Discussion}

Previous studies have reported various factors associated with mortality among TB patients [3] [7] [15]. TB drug resistance, HIV infection, diabetes mellitus, cancer, alcohol and malnutrition are among the frequently observed factors [15]. The risk of death is increasing with the number of those risk factors for the same patient.

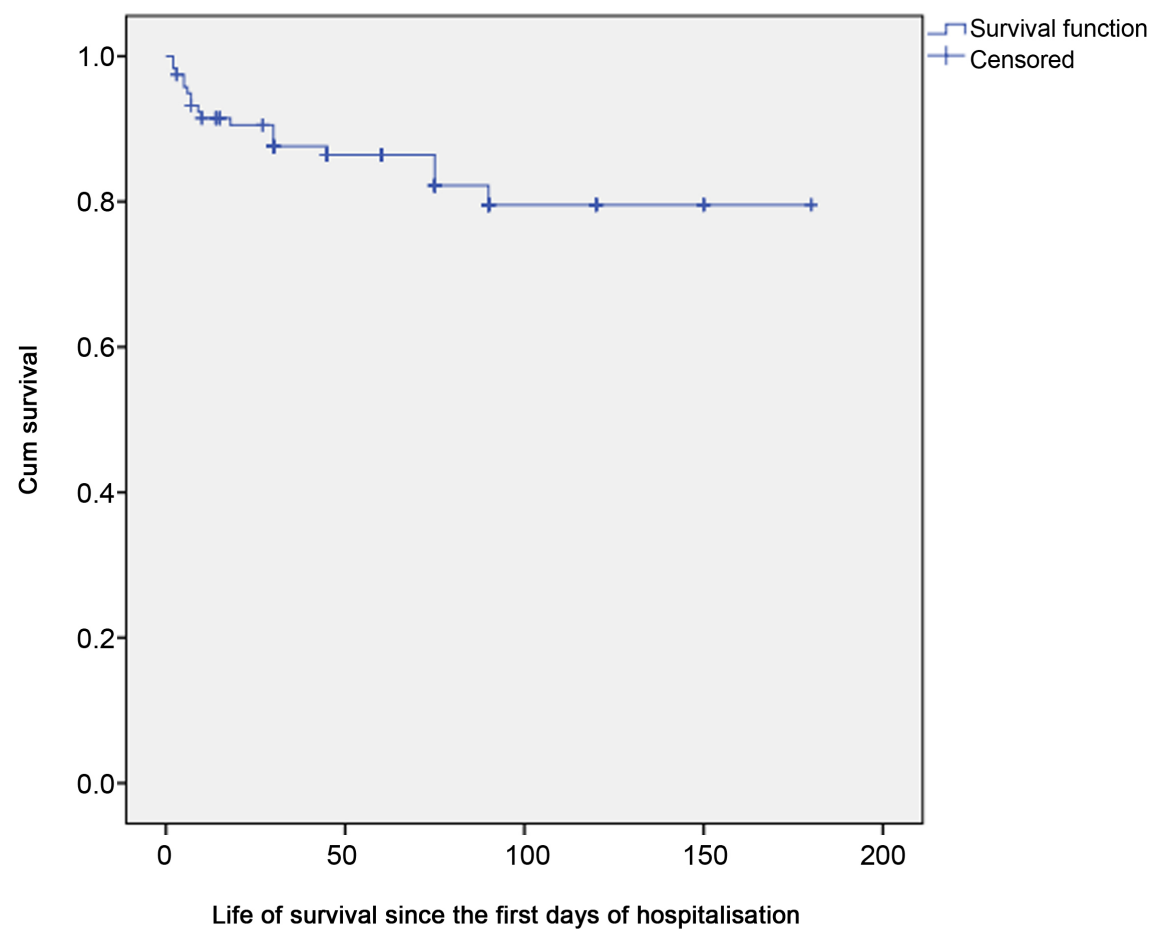

Figure 2. Global survival curve. 




Figure 3. Survival of patients according to the presence or absence of pulmonary fibrosis.

In this study, sociodemographic parameters did not have any effect on the survival of TB patients unlike previously reported studies [16] [17]. This discrepancy might be explained by the design of our study, which included only the patients with MDR/RR-TB and admitted in the referral hospital of Kinshasa.

In this study, many clinical signs were found in association with patients' death, these signs are related to a poor clinical evolution despite the specific anti TB therapy observed in ambulatory or out patient management. Some factors might explain this treatment failure, less compliance to treatment following side effects of medicines, inefficient directly observed treatment system (DOTS) or an inadequate TB regimen treatment, development of drug resistance other than MDR/RR-TB [14] [18]. A better management of treatment's side effects is a key for a successful compliance to treatment. It is recommended to assess a complete the treatment susceptibility at the starting of TB treatment, this assessment is crucial to ensure the effective treatment for patients [1] [4] [14]. There are currently some available rapid tests for treatment sensibility such as GenXpert (manufacturer, city), Line Probe Assay (Hain test), and these tools can detect early patients with other forms of TB drug resistance such pre-XDR TB or XDR TB [19] [20]. These tests should be extended to all TB patients with diagnosed MDR/RR-TB. 
Severe anemia was observed among all MDR/RR-TB patients, and was associated with death among TB patients [21]. Unlike previous reports, anemia was not associated with death in this study, all patients with suggestive signs of severe anemia received rapid care including blood transfusion at the Damien Excellence center, thus reducing considerably the risk of death due to anemia. Hyperleucocytosis was associated with death among TB patients in this study, systematically screening for other bacterial infections would reduce the risk of death due to sepsis [13] [22] [23]. We had identified nine cases of TB associated with sepsis, including 5 patients with blood culture positive for common bacteria. These patients had a low compliance to TB regimen treatment and a Chext $\mathrm{X}$-ray with bilateral tuberculous lung destruction, which might have provided a good environment for bacterial pneumonia.

Radiographic lesions were associated with mortality among TB patients in our study, especially fibrosis and combined alveolar and interstital syndrome. In Niger, Piubello had observed extended radiographic lesions without fibrosis, and the outcome of patients was better if compared with this study [14]. Fibrosis was observed among MDR/RR-TB patients in our study, and those lesions are suggestive of late TB diagnosis. Pulmonary fibrosis usually is associated with a chronic respiratory failure and a poor prognosis. Most patients enrolled in this study had at least two histories of tuberculosis prior to the diagnosis of MDR/RR-TB (Table 2). Molecular diagnostic tools to detect different form of TB drug resistance are currently available [14] [18] [19] [20]; these tests should be applied on the initial screening level for any suspected case of drug resistance, which would allow an early diagnosis with effective case management, and consequently poor degree of pulmonary sequels.

Complications were significantly associated with cases of death in our study; these complications included a poor nutritional status, chronic pulmonary heartdisease, chronic respiratory insufficiency and depression. Other factors such anemia, HIV infection and diabetes mellitus have been reported in previous works [16] [17] [21] [22] [23] [24] [25], nevertheless they were not significantly associated with death in this study. Pascopella et al. [26] have recommended to include the assessment of these common complication in the management and monitoring of TB and MDR/RR-TB patients.

Other associated morbidities such chronic obstructive bronchopneumonia, asthma, sepsis, malaria and thromboembolic pathologies were rather associated with increased morbidity than mortality of MDR/RR-TB patients (Table 4), this condition might be explained by the rapid case management in the Damien Excellent center with time effective diagnosis and treatment.

Five factors were associated with mortality in a multivariate analysis (Table 5), previous studies have also reported alcohol and pulmonary fibrosis as factors associated with premature death of TB patients [15] [27]. Asthenia was probably caused by a poor nutritional status of patients, the main co-morbidity observed in this study, Javais et al. have also reported similar results [28]. An appropriated 
management of malnutrition with protein-energetic nutrients would considerably improve the general status of TB and MDR/RR-TB patients [29]

Depression and smoking have been reported as factors associated with high mortality among TB patients [24] [30] [31] [32] unlike those studies, there was no significant association in the current study. The number of followed subjects in this study was smaller than in previous reports, which might explain the difference in the significance of some factors.

The survival rate of hospital-admitted patients was influenced by the presence of lung fibrosis, and Ralph et al. have reported similar results [27]. Therefore, it is crucial to initiate an early management of TB cases to prevent the pulmonary sequels that can cause chronic pulmonary insufficiency.

The current study has targeted only patients admitted in a referral hospital with MDR/RR-TB with a limited number of patients during the study window's time. A future study should integrate treatment outcomes of at a large scale of TB patients to increase the statistical power. Despite the limited number of subjects, this study could identify factors associated with poor outcomes of out-patient's management of MDR/RR-TB cases in Kinshasa, including the associated complications and co-morbidities.

\section{Conclusion}

Mortality among MDR/RR-TB patients in DRC can be reduced by an effective control of alcohol addiction, an improvement of nutritional status of patients with an appropriated dietetic regimen, early detection of drug resistance and appropriated management of diagnosed cases without delay to prevent irreversible complications. HIV infection, depression, chronic pulmonary heart disease and diabetes mellitus are potential co-morbidities susceptible to affect the outcome of MDR/RR-TB management, and should not be neglected to improve the life quality of patients. The national program against tuberculosis should include the management these risk factors in the strategic plans to reduce mortality.

\section{Acknowledgements}

The authors are grateful to Action Damien Foundation for the financial management of hospitalized patients and gratefully thank to professor Yombodan Justin Kalenda of Nagasaki University and to Doctor Nkodila Aliocha for statistical and critical analysis.

\section{Funding}

This work received no financial assistance from any funding agency in the public, commercial, or non-profit sectors.

\section{Competing Interest}

The authors declare that they do not have any financial interest with the information contained in this paper. 


\section{Ethics Approval}

The study protocol was approved by the ethical committee of the School of public health of the University of Kinshasa.

\section{References}

[1] World Health Organization (2016) Global Tuberculosis Report 2016. WHO, Geneva. http://www.who.int/tb/publications/global_report/en/

[2] Rapport du groupe thématique sur la tuberculose pharmacorésistante pour la revue externe à mi-parcours, PNLT RD Congo Décembre 2016.

[3] Chung-Delgado, K., Guillen-Bravo, S., Revilla-Montag, A. and Bernabe-Ortiz, A. () Mortality among MDR-TB Cases: Comparison with Drug-Susceptible Tuberculosis and Associated Factors. PLoS ONE, 10, e0119332. https://doi.org/10.1371/journal.pone.0119332

[4] Kashongwe, M.I., Bakebe, M.A., Nguen, O., Kabengele, B.O., Woyam, A., Bidiaka, M.C. and Kayembe, J.M. (2017) Evaluation thérapeutique de la tuberculose pulmonaire à bacille multirésistant: Etude de cohorte historique aux Cliniques Universitaires de Kinshasa. Annales Africaines de Médecine, 10, 2545-2550.

[5] Kashongwe, M.I., Mbulula, L., Bisuta, F.S., et al. (2015) Profil épidémiologique, bactériologique et évolutif des patients tuberculeux Multirésistants en traitement ambulatoire standardisé de 24 mois à Kinshasa, RD Congo. Revue de pneumologie tropicale, 7ème Congrès de la Saplf, Yaoundé, Octobre 2015, abstract AD1-19, p. 34.

[6] Guide de prise en charge de la tuberculose PATI-5, Programme National de Lutte contre la Tuberculose en République Démocratique du Congo, 2016.

[7] Gandhi, N.R., Andrews, J.R., Brust, J.C.M., Montreuil, R., Weissman, D., Heo, M., Moll, A.P., Friedland, G.H. and Shah, N.S. (2012) Risk Factors for Mortality among MDR- and XDR-TB Patients in a High HIV-Prevalence Setting. International Union against Tuberculosis and Lung Disease, 16, 90-97.

https://doi.org/10.5588/ijtld.11.0153

[8] World Health Organization (2016) Chest Radiography in Tuberculosis DetectionSummary of Current WHO Recommendations and Guidance on Programmatic Approaches. WHO Library Cataloguing-in-Publication Data, WHO/HTM/TB/2016.20.

[9] Bjelland, I., Dahl, A.A., Haug, T.T. and Neckelmann, D. (2002) The Validity of the Hospital Anxiety and Depression Scale: An Updated Literature Review. Journal of Psychosomatic Research, 52, 69-77. https://doi.org/10.1016/S0022-3999(01)00296-3

[10] Organisation Mondiale de la Santé (2016) Guide, lignes directrices unifiées sur la prévention, le diagnostic, le traitement et les soins du VIH pour les populations clé. Bureau régional de l'OMS pour l'Afrique, OMS juin.

[11] Organisation Mondiale de la Santé (2017) Rapport sur le paludisme dans le monde 2016: Résumé. OMS, Genève. (WHO/HTM/GMP/2017.4)

[12] Bakebe, A., Kashongwe, I., Mulenga, C., Tshiasuma, M., Kabengele, B., Bisuta, S.F., Makulo, J.R., Kashongwe, Z. and Kayembe, J.-M. (2017) Pulmonary Embolism: Epidemiologic Data and Diagnosis in Kinshasa. The International Journal of Tuberculosis and Lung Disease, 21, 875-879.

[13] Ferreira, F.L., Bota, D.P., Bross, A., et al. (2001) Serial Evaluation of the SOFA Score to Predict Outcome in Critically Ill Patients. JAMA, 286, 1754-1758.

[14] Piubello, A., Hassane Harouna, S., Souleymane, M.B., Boukary, I., Morou, S., Daouda, M., et al. (2014) Taux élevé de guérison sans rechute avec un traitement 
court standardisé de la tuberculose multirésistante au Niger. International Journal of Tuberculosis and Lung Disease, 18, 1188-1194.

[15] Sterling, T.R., Zhao, Z., Khan, A., Chaisson, R.E., Schluger, N., Mangura, B., et al. (2006) Mortality in a Large Tuberculosis Treatment Trial: Modifiable and Non-Modifiable Risk Factors. The International Journal of Tuberculosis and Lung Disease, 10, 542-549.

[16] Amnuaiphon, W., Anuwatnonthakate, A., Nuyongphak, P., et al. (2009) Factors Associated with Death among HIV-Uninfected TB Patients in Thailand, 2004-2006. Tropical Medicine \& International Health, 14, 1338-1346. https://doi.org/10.1111/j.1365-3156.2009.02376.x

[17] Horne, et al. (2010) Factors Associated with Mortality in Patients with Tuberculosis. BMC Infectious Diseases, 10, 258. https://doi.org/10.1186/1471-2334-10-258

[18] Georghiou, S.B., Seifert, M., Catanzaro, D.G., Garfein, R.S. and Rodwell, T.C. (2017) Increased Tuberculosis Patient Mortality Associated with Mycobacterium tuberculosis Mutations Conferring Resistance to Second-Line Antituberculous Drugs. Journal of Clinical Microbiology, 55, 1928-1937. https://doi.org/10.1128/JCM.00152-17

[19] Theron, G., Peter, J., Richardson, M., Barnard, M., Donegan, S., Warren, R., Steingart, K.R. and Dheda, K. (2014) The Diagnostic Accuracy of the GenoType MTBDRslassay for the Detection of Resistance to Second-Line Anti-Tuberculosis Drugs. Cochrane Database of Systematic Reviews, No. 10, CD010705. https://doi.org/10.1002/14651858.CD010705.pub2

[20] Clouse, K., et al. (2012) Implementation of Xpert MTB/RIF for Routine Point-of-Care Diagnosis of Tuberculosis at the Primary Care Level. South African Medical Journal, 102, 805-807. https://doi.org/10.7196/SAMJ.5851

[21] Isanaka, S., Mugusi, F., Urassa, W., Willett, W.C., Bosch, R.J., Villamor, E., Spiegelman, D., Duggan, C. and Fawzi, W.W. (2012) Iron Deficiency and Anemia Predict Mortality in Patients with Tuberculosis. Journal of Nutrition, 142, 350-357. https://doi.org/10.3945/jn.111.144287

[22] Waitt, C.J. and Squire, S.B. (2011) A Systematic Review of Risk Factors for Death in Adults during and after Tuberculosis Treatment. International Journal of Tuberculosis and Lung Disease, 15, 871-885. https://doi.org/10.5588/ijtld.10.0352

[23] Kawa, S.G., Gilarmo, R.H., et al. (2006) Tuberculosis Mortality, Drug Resistance, and Infectiousness in Patient with and without HIV Infection in PERU. The American Journal of Tropical Medicine and Hygiene, 75, 1027-1033.

[24] Reed, G.W., Choi, H., Lee, S.Y., Lee, M., Kim, Y., et al. (2013) Impact of Diabetes and Smoking on Mortality in Tuberculosis. PLOS ONE, 8, e58044.

https://doi.org/10.1371/journal.pone.0058044

[25] Baker, et al. (2011) The Impact of Diabetes on Tuberculosis Treatment Outcomes: A Systematic Review. BMC Medicine, 9, 81. https://doi.org/10.1186/1741-7015-9-81

[26] Pascopella, L., Barry, P.M., Flood, J. and Kathryn, D.R. (2014) Death with TB in California, 1994-2008. Open Forum Infectious Diseases, 1, ofu090.

[27] Ralph, A.P., Kenangalem, E., Waramori, G., Pontororing, G.J., Sandjaja, et al. (2013) High Morbidity during Treatment and Residual Pulmonary Disability in Pulmonary Tuberculosis: Under-Recognised Phenomena. PLOS ONE, 8, e80302. https://doi.org/10.1371/journal.pone.0080302

[28] Javaid, A., Shaheen, Z., Shafqat, M., Khan, A.H. and Ahmad, N. (2017) Risk Factors for High Death and Loss-to-Follow-up Rates among Patients with Multidrug-Resistant Tuberculosis at a Programmatic Management Unit. American Jour- 
nal of Infection Control, 45, 190-193. https://doi.org/10.1016/j.ajic.2016.07.026

[29] Danesh, J., et al. (2016) Body-Mass Index and All-Cause Mortality: Individual Participant-Data Meta-Analysis of 239 Prospective Studies in Four Continents. The Lancet, 388, 776-786.

[30] Liu, C.H., Li, L., Chen, Z., Wang, Q., Hu, Y.L., et al. (2011) Characteristics and Treatment Outcomes of Patients with MDR and XDR Tuberculosis in a TB Referral Hospital in Beijing: A 13-Year Experience. PLoS ONE, 6, e19399.

[31] Ugarte, G.C., Ruiz, P., Zamudio, C., Canaza, L., Otero, L., Kruger, H. and Seas, C. (2013) Association of Major Depressive Episode with Negative Outcomes of Tuberculosis Treatment. PLOS ONE, 8, e69514.

[32] Oh, K.H., Choi, H., Kim, E.J. and Cho, S.I. (2017) Depression and Risk of Tuberculosis: A Nationwide Population Based Cohort Study. The International Journal of Tuberculosis and Lung Disease, 21, 804-809.

https://doi.org/10.5588/ijtld.17.0038 